\title{
QUANDO ATROFIAR E DESQUALIFICAR SÃO CONDIÇÕES PARA MANUTENÇÃO DA SUBALTERNIDADE
}

\author{
WHEN TO DRUNK AND DISQUALIFY ARE CONDITIONS \\ FOR MAINTENANCE OF SUBALTERNITY \\ CUANDO REDUCIR Y DESCALIFICAR SON CONDICIONES \\ DE MANTENIMIENTO DE LA SUBALTERNIDAD
}

Maria Margarida Machado ${ }^{1}$

\begin{abstract}
RESUMO
As reflexões aqui apresentadas compartilham parte da tese defendida, para o concurso de titular da UFG, intitulada o Direito a escolarização e a manutenção da subalternidade, que tomou por objeto de análise a política de educação de jovens e adultos implementada no Brasil, principalmente após a promulgação da Constituição Federal de 1988. Foram acrescidas reflexões resultantes das angústias compartilhadas em outros espaços de diálogo, acompanhando as políticas de Educação de Jovens e Adultos (EJA) e Educação Profissional (EP) no Brasil, e que só se intensificaram, após o processo de impeachment com o Golpe de 2016 e os resultados das eleições de 2018. Para a construção deste artigo contamos com a contribuição de depoimentos de ex-alunos da EJA, que expressam o sentido do retorno à escolarização e os desafios por eles vividos; utilizamos a pesquisa bibliográfica relacionada à modalidade EJA integrada a EP e suas experiências específicas em Goiás; analisamos documentos oficiais, tais como leis, pareceres, projetos político-pedagógicos e dados fornecidos pelos órgãos oficiais, tais como Instituto Nacional de Estudos e Pesquisas Educacionais Anísio Teixeira (Inep) e Instituto Brasileiro de Geografia e Estatística (IBGE). O referencial teórico gramsciano é que dá o suporte principal às análises do texto. A história da educação nos revela em muitos momentos que o direito a educação não se efetiva, ou se concretiza como uma oferta de acesso precário ao conhecimento e de certificação aligeirada. Para o contexto em que estamos vivendo, é possível constatar que a atrofia da experiência Proeja também pode ser entendida pelo fato deste programa, que se pretendeu constituir em política, representar uma ameaça mesmo que de forma tímida e não massiva, ao projeto de formação para a subalternidade, tão necessário ao sistema capitalista desigual e combinado.
\end{abstract}

Palavras-Chave: Educação de jovens e adultos. Escolarização. Subalternidade. Política educacional.

\begin{abstract}
The reflections presented here share part of the thesis defended for the UFG holder contest, entitled The Right to Schooling and the Maintenance of Subalternity, which took as its object of analysis the policy of youth and adult education implemented in Brazil, especially after the promulgation of the Federal Constitution of 1988. Reflections resulting from shared anguish in other spaces of dialogue were added, accompanying the policies of Youth and Adult Education (EJA) and Vocational Education (VE) in Brazil, and which only intensified after the process. impeachment with the 2016 coup and the results of the 2018 elections. For the construction of this article we counted on the contribution of testimonials from EJA alumni, which express the meaning of the return to school and the challenges they experienced; We used the bibliographic research related to the EJA modality integrated to VE (Proeja) and its specific experiences in Goiás; We analyze official documents, such as laws, opinions, political-pedagogical projects and data provided by official bodies, such as Anísio Teixeira National Institute for Educational Studies and Research (Inep) and the Brazilian Institute of Geography and Statistics (IBGE). The Gramscian theoretical framework provides the main support for the analysis of the text. The history of education reveals to us in many moments that the right to education is not effective, or materialized as an offer of precarious access to knowledge and certification. For the context in which we are living, it can be seen that the atrophy of the Proeja experience can also be understood by
\end{abstract}

1 Universidade Federal de Goiás (UFG). Goiânia - GO, Brasil. ORCID: http://orcid.org/0000-0002-5036-4334. E-mail: mmm2404@gmail.com

Artigo recebido em outubro de 2019. Aprovado em novembro de 2019.

Cad. Pesq., v. 26, n. 4, out./dez., 2019. 
the fact that this program, which was intended to constitute politics, represents a threat, even if timidly and non-massively, to the training project for subordination, so necessary to the unequal and combined capitalist system.

Keywords: Youth and adult education. Schooling. Subalternity. Educational politicy.

\section{RESUMEN}

Las reflexiones presentadas aquí comparten parte de la tesis defendida para el concurso de profesor titular de la UFG, titulado El derecho a la escolarización y el mantenimiento de la subalternidad, que tuvo como objeto de análisis la política de educación de jóvenes y adultos (EJA) implementada en Brasil, especialmente después de la promulgación de la Constitución Federal de 1988. Se agregaron reflexiones resultantes de la angustia compartida en otros espacios de diálogo, acompañando las políticas de Educación de Jóvenes y Adultos (EJA) y Formación Profesional (FP) en Brasil, y que solo se intensificaron después del proceso de juicio político con el Golpe de 2016 y los resultados electorales del 2018. Para la construcción de este artículo contamos con la contribución de testimonios de antiguos alumnos de EJA, que expresan la sensación de regreso a la escuela y los desafíos que experimentaron; Utilizamos la investigación bibliográfica relacionada con la modalidad EJA integrada a la FP (Proeja) y sus experiencias específicas en el estado de Goiás; Analizamos documentos oficiales, como leyes, normativas, proyectos político-pedagógicos y datos proporcionados por organismos oficiales, como el Instituto Nacional de Estudios e Investigación Educativa Anísio Teixeira (Inep) y el Instituto Brasileño de Geografía y Estadística (IBGE). El marco teórico gramsciano proporciona el soporte principal para el análisis del texto. La historia de la educación nos revela muchas veces que el derecho a la educación no se realiza o si materializa como una oferta de acceso precario al conocimiento y la certificación. Para el contexto en el que vivimos, se puede ver que la atrofia de la experiencia Proeja también se puede entender por el hecho de que este programa, que pretendía constituir política, representa una amenaza, aunque sea tímidamente y no masivamente, para el proyecto de capacitación para subordinación, tan necesaria para el sistema capitalista desigual y combinado.

Palabras clave: Educación de jóvenes y adultos. Escolaridad Subalternidad Política educativa.

\section{Introdução}

As reflexões aqui apresentadas compartilham parte da tese defendida, em novembro do ano passado, para o concurso de professora titular da UFG, intitulada - Direito a escolarização e a manutenção da subalternidade. Foram acrescidas mais algumas reflexões, resultantes das angústias compartilhadas em outros espaços de diálogo, e que vêm se acumulando, desde há alguns anos acompanhando as políticas de EJA e EP no Brasil, e que só se intensificaram, após o processo de impeachment com o Golpe de 2016 e os resultados das eleições do ano passado.

A exposição foi motivada a partir da seguinte questão: Proeja FIC Fundamental e Proeja Ensino Médio: se ampliar é preciso, por que estão sendo atrofiados? Eu inicialmente respondo a esta questão afirmando: porque atrofiar e desqualificar a educação são instrumentos de quem está no poder, para manter a subalternidade. Eu diria que as manchetes dos últimos nove meses corroboram com esta minha resposta. Mas, não podemos olhar a questão apenas a partir do Tsunami Governo Jair Messias Bolsonaro. É preciso recuar um pouco mais e entender como a pauta da educação de jovens e adultos trabalhadores experimenta em sua historicidade, em diferentes contextos, o que podemos aqui denominar de processos de subalternização dos sujeitos, ou ainda políticas que contribuem para a subalternidade, tomando como referência este conceito em Gramsci (2002).

Como o contexto que nos convida a pensar: Regressão social e resistência da classe trabalhadora, creio ser oportuno elucidar algumas questões de contexto das políticas educacionais que nos convocam a resistência, para em seguida fixarmos uma lente mais específica na educação de jovens e adultos trabalhadores.

É preciso resistir ao desmonte da escola pública. Para isso, creio que precisamos considerar que não é possível enxergar e nem mesmo tentar compreender as acusações, por exemplo de doutrinadores, aos profissionais das instituições públicas, do ponto de vista político, sem que de fato as encaremos na sua intrínseca relação com os interesses 
que elas realmente representam, que são os interesses econômicos. Tais interesses vão além de questionar o que fazem ou deixam de fazer professores de universidade e institutos federais em sua ação docente, em suas pesquisas ou nas atividades de extensão; ou ainda, o que fazem e como fazem para mediar conhecimentos e produzir conhecimentos os professores que atuam com crianças, adolescentes, jovens, adultos e idosos na Educação Básica. É sobre estes interesses que penso ser necessários conversarmos inicialmente.

Acredito que o debate que está colocado para a educação brasileira hoje, em especial para a educação pública, é muito mais do que se somos ou não somos doutrinadores. Esta é apenas a "cortina de fumaça" que encobre os verdadeiros interesses em jogo, quando reconstituímos os temas que envolveram a área da educação, sobretudo nos últimos nove anos. Cabe lembrar que nas conferências nacionais de educação de 2010 e 2014, e durante quase quatro anos, discutimos exaustivamente a aprovação do atual Plano Nacional de Educação (PNE), sob ataques dos discursos esbravejantes de que, aos defensores do PNE, interessava a doutrinação ideológica nas escolas, por isso a defesa de vários deputados e senadores no Congresso Nacional à chamada "Escola Sem Partido". Mas, esbravejar mesmo foi o que ouvimos, naquele mesmo contexto, e segue na narrativa deste "novo/velho" congresso, eleito em 2018 , de que para o bem da família e do país o que deve ser combatido na educação brasileira é a chamada "ideologia de gênero".

Avalio que esses dois temas, que identifico também como cortina de fumaça utilizada estrategicamente no Congresso Nacional, naquele período, para desviar o olhar da sociedade sobre questões fundamentais, para o fortalecimento da área da educação como política de Estado e não de governo, serviram e continuam servindo até hoje para encobrir a verdadeira razão dos ataques a quem defende a educação pública, laica, gratuita e de qualidade social para todas e todos.

Esta razão é sem sombra de dúvidas o interesse evidente no acesso irrestrito aos recursos públicos, vinculados constitucionalmente para Educação, por parte dos empresários da educação, de olho num orçamento bilionário que está previsto para atender da educação infantil à pós-graduação no país. 117 bilhões de reais que representam hoje em torno de $1,2 \%$ do Produto Interno Bruto (PIB) para educação, considerando apenas o orçamento da União, segundo dados do Portal da Transparência ${ }^{2}$. Ocorre que se este orçamento já é atrativo para olhos gananciosos dos empresariados da educação, imaginem os orçamentos de estados, municípios e o Distrito Federal que representam os outros $4,8 \%$ do PIB destinados a educação.

Por trás dos discursos de assepsia ideológica e moral, que querem se tornar hegemônicos, estão os interesses de acesso sem limites a esses vultuosos recursos, conquistados a duras penas para a educação brasileira, ao longo de muitas lutas históricas e reafirmados como direito na Constituição Federal de 1988. Como já afirmava Cury (2002),

A importância da lei não é identificada e reconhecida como um instrumento linear ou mecânico de realização de direitos sociais. Ela acompanha o desenvolvimento contextuado da cidadania em todos os países. A sua importância nasce do caráter contraditório que a acompanha: nela sempre reside uma dimensão de luta. Luta por inscrições mais democráticas, por efetivações mais realistas, contra descaracterizações mutiladoras, por sonhos de justiça. (p. 247)

A operacionalização de mecanismos de políticas públicas para o uso dos recursos da educação pela União, Estados, Municípios e Distrito Federal é igualmente histórica: só para identificar algumas iniciativas, no campo da Educação Básica, é fundamental que se compreenda o significado da política de destinação de recursos via fundos, como Fundef e Fundeb; da extensão da obrigatoriedade da educação, com a EC 59/2009; dos Planos Nacionais de Educação, se desdobrando em planos estaduais, municipais e

Disponível em: <http://www.portaltransparencia.gov.br/funcoes/12-educacao?ano=2019> 
distrital; do debate importante sobre o Custo Aluno Qualidade; da defesa do aumento do investimento na educação, tendo como referência a chegada a 2024 em 10\% do PIB; da defesa feita sobre destinação dos recursos advindos do Pré-Sal para educação.

Enfim, não foram poucas as estratégias traçadas nos últimos 30 anos, após a aprovação do primeiro texto da CF/1988, para buscar regulamentar a efetividade da aplicação dos recursos constitucionais vinculados, a fim de que esses chegassem ao chão das escolas, que viabilizassem planos de cargos e salários para professores e demais profissionais da educação, mas sobretudo, que permanecessem na tarefa prioritária de melhoria da educação pública brasileira. Mas, isto sempre esteve em disputa.

A disputa de narrativa moralizante que vivenciamos desde o debate e aprovação do PNE até hoje, nada mais é do que estratégia para desqualificar o que fazemos na educação pública, enquanto o Ministério da Educação e o Congresso Nacional, por diferentes meios autorizam os recursos públicos da educação serem repassados para os representantes legitimadores do discurso ora se pretende hegemônico no país: são os militares, os líderes religiosos, as fundações e institutos vinculadas ao sistema financeiro e aos empresários do ensino, os principais beneficiários deste discurso e que tem a clara intenção de influenciar nos rumos da destinação do orçamento da educação pública hoje.

Mecanismos para isto já existem. Quando não ganham diretamente, pela via das bolsas, por exemplo, ou assumindo a gestão das próprias instituições públicas; ganham indiretamente na formação de professores, na produção de material didático, nas inúmeras estratégias que envolvem a dinâmica assumida pelos estados e municípios, seja por exemplo, para implantação da Reforma do Ensino Médio, seja para a padronização do fazer pedagógico pela via da Base Nacional Comum Curricular.

Eu diria que este é o contexto mais geral das "atrofias" que enfrentamos cotidianamente na educação pública brasileira, nesta conjuntura de fortes regressões sociais que nos convoca a resistir, enquanto trabalhadores da educação. Estar aqui neste colóquio, insistir em nos encontrarmos, compartilhar conhecimentos produzidos, é também uma forma de resistência. Claro que não é suficiente! Não há resistência de uma categoria profissional isolada, que consiga enfrentar o desmonte do Estado brasileiro que estamos presenciando, precisamos nos juntar aos demais trabalhadores, precisamos disputar a narrativa, mas sobretudo, precisamos ocupar as ruas, reorganizarmos as pautas de luta, nos reorganizarmos coletivamente. A educação pública que eles tentam destruir resistirá por nossas mãos. Temos a consciência de que o conhecimento é a nossa maior arma.

É com esta introdução que passo agora a refletir de maneira mais detida a questão da educação de jovens e adultos trabalhadores, que não está isenta de todas as questões já mencionadas. Mas, quando nos aproximamos de sua história, temos que reconhecer, com um certo "pessimismo da inteligência", como diria Gramsci, o quanto a escolarização voltada para esses sujeitos vem cumprindo um papel de manutenção de subalternidade dos trabalhadores.

\section{As atrofias também causadas nas ofertas da Educação de Jovens e Adultos}

A discussão sobre reformas educacionais que resultam na manutenção da subalternidade está muito evidente nas reflexões de Gramsci (2000, p. 49-50), quando ele analisa o resultado das reformas na Itália, no início do Século XX, que resultaram na multiplicação de escolas profissionalizantes que negavam aos trabalhadores o direito a formação geral.

A multiplicação de tipos de escola profissional, portanto, tende a eternizar as diferenças tradicionais; mas, dado que tende, nestas diferenças, a criar estratificações internas, faz nascer a impressão de ter uma tendência democrática. Por exemplo: operário manual e qualificado, camponês e agrimensor ou pequeno agrônomo, etc. Mas a 
tendência democrática, intrinsecamente, não pode significar apenas que um operário manual se torne qualificado, mas que cada "cidadão" possa tornar-se "governante" e que a sociedade o ponha, ainda que "abstratamente", nas condições gerais de poder fazê-lo: a democracia política tende a fazer coincidir governantes e governados (no sentido de governo com o consentimento dos governados), assegurando a cada governado o aprendizado gratuito das capacidades e da preparação técnica geral necessárias a essa finalidade.

Sob essa perspectiva, deveria ser pensada a formação de jovens e adultos como cidadãos que, em tese, podem tornar-se governantes. Não é possível desconhecer o prejuízo para a formação da classe trabalhadora, quando a escola que lhe é garantida não the confere essa formação, quando as características básicas da condição de trabalhador sequer são consideradas. Pensando que, "democracia política tende a fazer coincidir governantes e governados", os aligeiramentos dos processos educativos presentes nas experiências da EJA no Brasil contribuem para não se consolidar essa democracia.

Por todos esses elementos é que se faz necessário considerar que uma política de EJA no Brasil, coerente com princípios democráticos e da formação humana integral, não se resolve por meio de programas compensatórios. Não se pode tratar a população que demanda a Educação Básica como "residual" e, muito menos, considerar que o aligeiramento seja o caminho apropriado para essa formação integral. Essas reflexões nos remetem a dois outros elementos: quem é a maioria dessa população que está na EJA e como vem sendo atendida.

O depoimento de alguns alunos e ex-alunos da EJA podem nos ajudar a compreender isso,

Comecei a estudar com sete anos de idade, morava na roça, no município de Patrocínio - MG. A escola era longe da minha casa, precisava caminhar muito, com chuva ou sol, eu tinha muito medo mas, mesmo assim gostava de estudar, estudei até $03^{\circ}$ ano primário.

Com onze anos eu parei de estudar porque meu pai não tinha condição de pagar colégio e pensão para mim na cidade. Isso foi em 1952, os anos passaram eu me casei tive sete filhos e sempre morando na roça.

Em 1968 vim morar no Gama-DF, aqui meus filhos cresceram, estudaram e todos já estão casados, eu estava me sentindo muito sozinha. Voltar a estudar foi muito bom para mim. Em 1999 comecei fazendo supletivo, em 2000 conclui o $1^{\circ} \mathrm{grau}$, hoje estou fazendo matérias do $1^{\circ}$ ano do Ensino Médio. Estou com 60 anos, mas eu sinto aquela mesma vontade de estudar e aprender que tinha antes com onze anos.

A experiência de conviver com jovens, com os professores, está sendo muito boa. Em casa tem exercícios para fazer, as apostilas para estudar, eu já não me sinto mais sozinha, os livros são uma ótima companhia. Ao conviver com os jovens na sala de aula eu percebo a falta de interesse deles em estudar e aprender. Muitos querem copiar os exercícios que o colega fez, tirar cópia dos trabalhos já prontos, não gostam de ler, estão terminando o ensino médio sem saber quase nada. O ensino está defasado, o tempo é pouco e diminuiu muito o conteúdo. É muito difícil para esses jovens entrar no mercado de trabalho, porque o pouco que eles aprendem não dá para concorrer com os outros que estudam de fato.

Eu vou me esforçar ao máximo para conseguir aprender o conteúdo de todas as matérias e concluir o ensino médio e quem sabe eu possa até continuar fazendo outros cursos, é um pensamento que pode tornar-se realidade, só depende de mim. Gasparina Maria Antunes (62 anos)

Esse texto foi escrito por minha mãe que aos 62 anos concluiu o Ensino Médio em 2002 em cursos ainda denominados supletivo no Distrito Federal. É uma narrativa que cumpre aqui uma dupla função: a de reconhecer ainda o valor dessa história, mesmo já se tendo passado dezessete anos, desde que ela foi escrita por alguém que conclui 
o Ensino Médio com mais de sessenta anos; e a de dialogar com a história de outras tantas Gasparinas que, retornando à escolarização depois de adultas, têm muito a dizer do que viveram e do que esperavam da escola, para onde retornaram depois de muitos anos de ausência.

Mas a narrativa diz mais... fala de um encontro de gerações nessa $E J A$, há muito já anunciado pelas pesquisas que apontam a juvenilização da EJA no Brasil ${ }^{3}$. Há um sentimento contraditório de estar bem, por estar com a juventude, mas achar que eles "não querem nada" com os estudos. Críticas e julgamentos à parte, sobretudo quando reforçam preconceitos intergeracionais; o que é inegável é o tamanho dessa juvenilização e o que ela tem a nos dizer, não apenas sobre a EJA, mas sobre a educação brasileira que, sobretudo nos últimos anos, vem transferindo, cada vez mais, adolescentes e jovens para a modalidade da EJA, sem a preocupação necessária com o que isso representa para essa geração, que se forma sem o direito de aprender o que de fato a escola tem para oferecer em termos de conhecimentos sistematizados. Mais grave do que a transferência automática para EJA é a constatação do número de brasileiros de 15 anos e mais fora da escola, como constatado no Quadro 1.

Quadro 1 - População de 15 anos e mais fora da escola por faixa etária - Brasil, 2007 a $2015^{4}$

\begin{tabular}{|c|c|c|c|c|c|c|c|c|}
\hline Faixa Etária & 2007 & 2008 & 2009 & 2011 & 2012 & 2013 & 2014 & 2015 \\
\hline 15 a 17 anos & 1.998 .463 & 1.848 .162 & 1.716 .630 & 1.768 .612 & 1.735 .372 & 1.674 .105 & 1.712 .994 & 1.543 .713 \\
\hline 18 a 24 anos & 8.754 .140 & 8.170 .842 & 7.713 .001 & 7.499 .208 & 7.450 .854 & 7.152 .038 & 7.104 .830 & 6.702 .946 \\
\hline 25 a 29 anos & 7.206 .626 & 6.949 .249 & 6.589 .602 & 6.169 .374 & 5.980 .237 & 5.607 .296 & 5.534 .863 & 5.175 .518 \\
\hline 30 a 40 anos & 17.445 .620 & 16.918 .228 & 16.663 .704 & 16.394 .833 & 16.055 .629 & 15.680 .714 & 15.284 .627 & 14.962 .886 \\
\hline 41 a 50 anos & 15.289 .452 & 15.256 .798 & 14.746 .932 & 15.022 .939 & 15.089 .723 & 14.811 .996 & 15.077 .831 & 14.790 .943 \\
\hline 51 a 64 anos & 16.164 .913 & 16.690 .341 & 16.841 .363 & 18.171 .030 & 18.531 .673 & 19.137.794 & 19.410 .258 & 19.778 .537 \\
\hline 64 anos e mais & 11.538 .583 & 12.242 .653 & 12.506 .311 & 13.362 .804 & 13.994 .589 & 14.420 .122 & 15.221 .066 & 16.100 .831 \\
\hline Total & 78.397.797 & 78.076 .273 & 76.777 .543 & 78.388 .800 & 78.838 .077 & 78.484 .065 & 79.346.469 & 79.055 .374 \\
\hline
\end{tabular}

Fonte: Elaborado a partir dos dados do IBGE (2007 a 2015) disponibilizados no Laboratório de Dados Educacionais - UFPR

Considerando em 2015 apenas a faixa etária adolescente e jovem, estamos diante de mais de 12 bilhões de brasileiros entre 15 e 29 anos que não concluíram a educação básica e estão fora da escola. Essa realidade ainda indica que, o depoimento da idosa que concluiu seu Ensino Médio já cercada de jovens, seria outro se o direito a educação estivesse sendo assegurado, pelo menos a estes sujeitos. Seria preciso pensar em, no mínimo, triplicar a matrícula da EJA existente, para incorporá-los, pois em 2016 essa matrícula, incluindo todas as idades como pode ser constatado no Quadro 2

Quadro 2 - Matrículas da EJA no Brasil, no período de 2007 a 2016*

\begin{tabular}{|c|c|c|c|c|c|c|c|c|}
\hline \multirow{2}{*}{ Ano } & \multicolumn{4}{|c|}{ Ensino Fundamental } & \multicolumn{3}{|c|}{ Ensino Médio } & Total Geral \\
\cline { 2 - 9 } & $\begin{array}{c}\text { Anos } \\
\text { Iniciais }\end{array}$ & $\begin{array}{c}\text { Anos } \\
\text { Finais }\end{array}$ & $\begin{array}{c}\text { Integrado à Educação } \\
\text { Profissional }\end{array}$ & Total & Médio & $\begin{array}{c}\text { Integrado à Educação } \\
\text { Profissional }\end{array}$ & Total & \\
\hline 2007 & 1.160 .879 & 2.206 .153 & - & 3.367 .032 & 1.608 .599 & 9.747 & 1.618 .346 & 4.985 .378 \\
\hline 2008 & 1.127 .077 & 2.164 .187 & 3.976 & 3.295 .240 & 1.635 .245 & 14.939 & 1.650 .184 & 4.945 .424 \\
\hline 2009 & 1.035 .610 & 2.055 .286 & 3.628 & 3.094 .524 & 1.547 .275 & 19.533 & 1.566 .808 & 4.661 .332 \\
\hline 2010 & 923.197 & 1.922 .907 & 14.126 & 2.860 .230 & 1.388 .852 & 38.152 & 1.427 .004 & 4.287 .234 \\
\hline 2011 & 935.084 & 1.722 .697 & 23.995 & 2.681 .776 & 1.322 .422 & 41.971 & 1.364 .393 & 4.046 .169 \\
\hline 2012 & 870.181 & 1.618 .587 & $72.245^{* *}$ & 2.561 .013 & 1.309 .871 & 35.993 & 1.345 .864 & 3.906 .877 \\
\hline 2013 & 832.754 & 1.551 .438 & 63.600 & 2.447 .792 & 1.283 .609 & 41.269 & 1.324 .878 & 3.772 .670 \\
\hline 2014 & 774.352 & 1.451 .627 & 58.143 & 2.284 .122 & 1.265 .911 & 42.875 & 1.308 .786 & 3.592 .908 \\
\hline 2015 & 688.185 & 1.367 .823 & 67.394 & 2.123 .402 & 1.269 .984 & 39.060 & 1.309 .044 & 3.432 .446 \\
\hline 2016 & 628.393 & 1.356 .141 & 63.048 & 2.047 .582 & 1.341 .841 & 32.704 & 1.374 .545 & 3.422 .127 \\
\hline
\end{tabular}

Fonte: Sinopse Estatística da Educação Básica do INEP (BRASIL, 2016)

\footnotetext{
3 Dentre elas Abramo e Branco (2005); Spósito (1992, 2006); Carrano (2007); Fávero, Spósito, Carrano e Novaes (2007).

4 Os dados de série histórica, disponibilizados no LDE, ainda não contemplam os anos de 2016 a 2018.
}

Cad. Pesq., São Luís, v. 26, n. 4, p. 156-168, out./dez. 2019. 
*1) Não inclui matrículas de atendimento complementar e atendimento educacional especializado (AEE);
2) Educação de Jovens e Adultos inclui matrículas de EJA presencial e semipresencial.
** Os dados do ProJovem passaram a ser coletados na matrícula da EJA em 2012.

Estes dados de matrículas do Ensino Fundamental e do Ensino Médio da EJA revelam a tendência de queda de matrícula, que já fora observada nos estudos sobre a modalidade, principalmente a partir da implantação do Fundeb em 2007. Passados dez anos da implantação do fundo, que considera a matrícula da EJA para a redistribuição contábil do financiamento no âmbito dos recursos estaduais, essa medida não provoca impacto positivo de aumento da matrícula na modalidade. O que a Sinopse de 2016 revela é a perda de cerca de um milhão e meio de matrículas no Ensino Fundamental e no Ensino Médio da EJA, se comparamos com os dados de matrícula de 2007.

A análise dos dados dos Quadros 1 e 2 indica que a redução de matrícula na modalidade EJA não pode ser interpretada como conclusão de escolaridade da população de 15 anos e mais, pois aumenta a cada ano o número das pessoas que estão fora da escola e sem concluir a Educação Básica, principalmente entre os adultos e idosos. Portanto, se pensarmos na escola como um espaço importante para acesso e produção de novos conhecimentos, também os outros mais de 60 milhões de adultos e idosos deveriam ter direito a conclusão da educação básica.

Por fim, uma última reflexão, também a partir do depoimento da ex-aluna da EJA, diz respeito ao que significa, hoje, estar na EJA: "O ensino está defasado, o tempo é pouco e diminuiu muito o conteúdo". Com essa avaliação de quem fala de dentro do processo formativo, é necessário reconhecer que, infelizmente, a legislação que trata da EJA, vigente no país, reforça uma dimensão aligeirada de escolarização. A começar por considerar tempo algo que precisa ser abreviado porque "os alunos têm pressa", como afirmam muitos gestores, quando interrogados do porquê de os cursos de EJA serem ofertados em tempo reduzido. O texto das Diretrizes Operacionais para EJA, na Resolução CNE/CEB nº 03/2010, é a sustentação legal para esse tempo reduzido, no Artigo $4^{\circ}$ onde indica os mínimos de 1.600 (mil e seiscentas) horas para os anos finais do Ensino Fundamental e 1.200 (mil e duzentas) horas para o Ensino Médio (BRASIL, 2010b).

Esta carga horária mínima acaba sendo a máxima praticada pelas redes de ensino nos estados e municípios, o que vem sendo avaliado como um aspecto negativo pelos próprios estudantes da EJA. Embora o discurso esboçado no Parecer CEB/CNE $n^{\circ}$ 6/2010, que fundamenta a Resolução CEB/CNE n 03/2010 (BRASIL, 2010b), indique a necessidade de propostas experimentais de atendimento ao público da EJA, o que ainda prevalece, nas redes municipais e estaduais, é a reedição do modelo suplência, apenas com o nome de EJA.

1. Organização de propostas experimentais para atendimento às demandas específicas de organização do trabalho pedagógico nas escolas e sistemas, especialmente para a população do campo, indígenas, quilombolas, ribeirinhos, pessoas privadas de liberdade ou hospitalizadas, dentre outros, devendo cada proposta experimental receber autorização do órgão do respectivo sistema. [...] 2. Aproveitamento de estudos realizados antes do ingresso nos cursos de EJA, bem como os critérios para verificação do rendimento escolar devem ser garantidos, tal como prevê a LDB, e transformados em horas-atividades a serem incorporados no currículo escolar do (a) estudante, o que deve ser comunicado ao respectivo sistema de ensino. (BRASIL, 2010 a, p. 26)

O segundo aspecto indicado no item do Parecer CEB/CNE n 06/2010: "E prevêse a possibilidade de:", também não se encontra materializado nos currículos de EJA praticados na maioria das experiências do país. As medidas de aproveitamento de estudos e de verificação de rendimentos escolares, que deveriam valorizar os conhecimentos adquiridos anteriormente pelos alunos, têm sido utilizadas por outro lado para apressar a passagem e a saída dos jovens e dos adultos das escolas, como 
verificamos no uso dos exames de classificação e reclassificação. Uma das poucas experiências em que os conhecimentos fora da escola são validados pelos sistemas educacionais, especificamente na rede dos institutos federais, é o Programa Certific ${ }^{5}$, todavia esses conhecimentos adquiridos na vida profissional não são considerados nos currículos da EJA.

Nãoé possível desconsiderar, nesta reconstituição histórica, que houve experiências em EJA que se atentaram às demandas por tempos diferenciados e currículos que integram formação geral e formação profissional. O Programa Nacional de Integração da Educação Profissional com a Educação Básica na Modalidade de Educação de Jovens e Adultos (Proeja), em muitas ofertas suscitou e continua suscitando interesse dos pesquisadores em buscarem compreender o sentido desta experiência para EJA ${ }^{6}$. Todavia, a experiência desse programa, tanto no ensino fundamental quanto no ensino médio, ainda é residual na realidade da oferta de EJA, como demonstram os dados do documento de monitoramento das metas do PNE 2014-2024 (2018) elaborado pelo Inep.

Quando se refere especificamente à Meta 10 do PNE, que previa "Oferecer, no mínimo, $25 \%$ (vinte e cinco por cento) das matrículas de educação de jovens e adultos, nos ensinos fundamental e médio, na forma integrada a educação profissional" (BRASIL, 2014), verificamos que essa oferta cresce no Ensino Fundamental de forma estrondosa, se observarmos os dados de 2011 para 2012, porém nada mais é do que a vinda das matrículas do Programa de Inclusão de Jovens (ProJovem) que passaram a ser contabilizadas pelo Inep como EJA. Verificamos também que no Proeja Médio a oferta decresce a partir de 2015.

Chegamos ao ponto de voltar à pergunta desta mesa: se ampliar é preciso, por que estão sendo atrofiados? Observem o que indica o relatório do $2^{\circ}$ ciclo de monitoramento do PNE elaborado pelo Inep (BRASIL, 2018),

Gráfico1 - Matrícula de EJA integrada à Educação Profissional de 2010 a 2017 por regiões do país

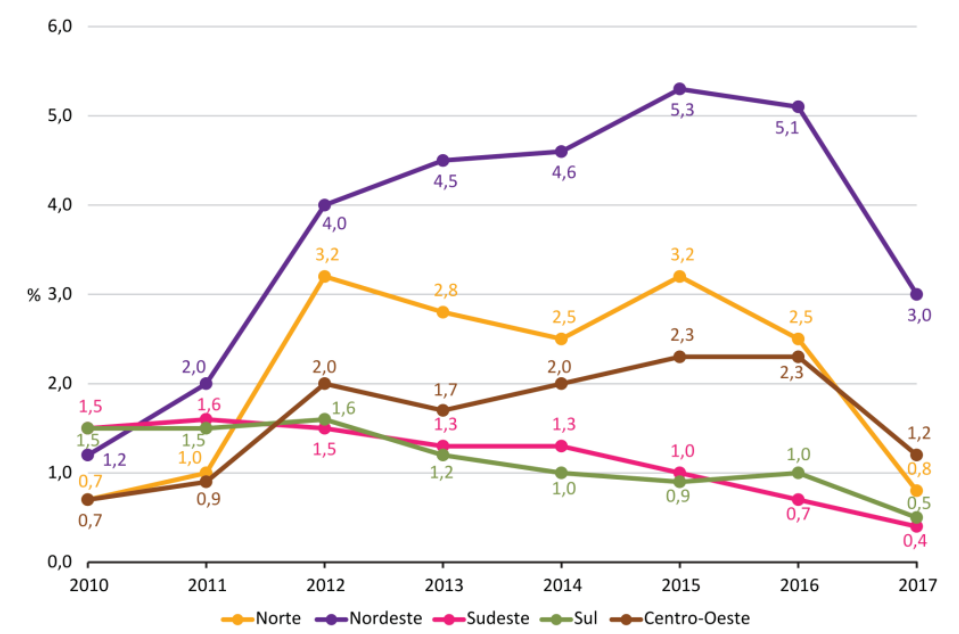

Fonte: Publicação INEP (BRASIL, 2018, p. 183)

O Gráfico 1 revela o movimento de picos de aumento de matrícula a partir de 2010 e de refluxo dessas até 2017, observado em todas as regiões do país, inclusive na Região Nordeste onde a presença dos cursos de EJA integrados a EP é a maior em termos quantitativos. A matrícula do Rio Grande do Norte, por exemplo, era de 5.001 alunos em 2016 e caiu para 1.567 em 2017. Um estudo mais detalhado sobre esta redução vai indicar um refluxo nas propostas de cursos FIC com o fim do Pronatec.

Nesse mesmo relatório, é possível constatar a participação das redes de ensino na oferta da EJA integrada a EP. Podemos verificar em nível nacional que, mesmo a

\footnotetext{
5 Disponível em: <http://portal.mec.gov.br/setec-secretaria-de-educacao-profissional-e-tecnologica/programas?id=15266>

6 Oliveira et al. (orgs), 2014; Rêses et al. (orgs). 2017; Rodrigues e Machado (orgs.), 2018.
} 
pequena oferta desta modalidade, está concentrada nas redes públicas, com destaque, para maior participação dos estados e com um grande refluxo dos municípios entre os anos de 2016 a 2017, como pode ser observado no Gráfico 2.

Gráfico 2 - Distribuição percentual das matrículas da EJA integrada a EP, por dependência administrativa, Brasil - 2010 a 2017

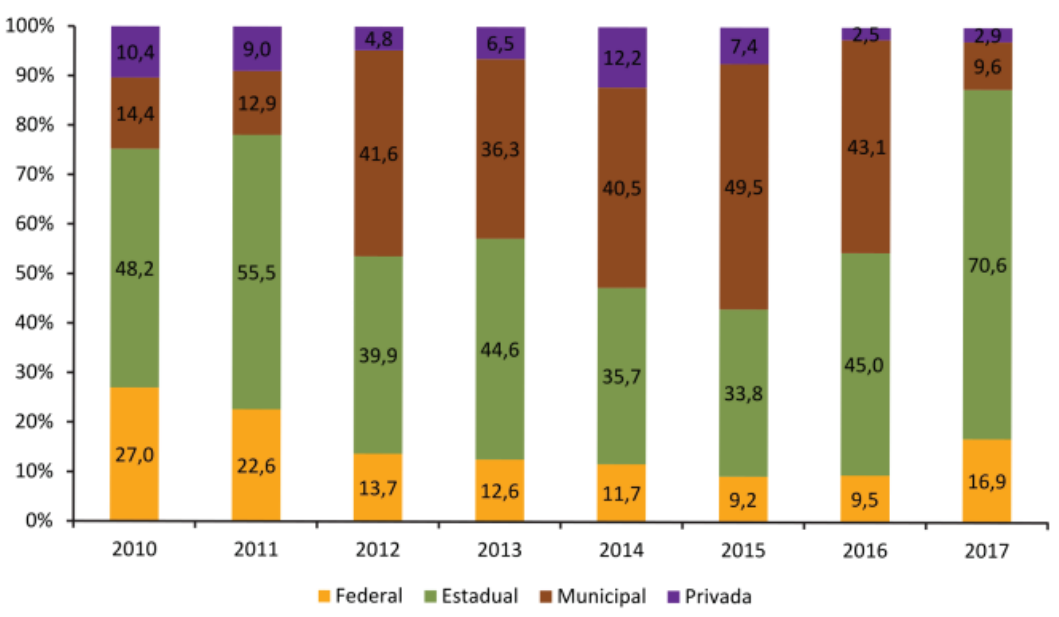

Fonte: Publicação INEP (BRASIL, 2018, p. 186)

A análise dos técnicos do Inep destacam a difícil situação de cumprimento de várias das metas do PNE 2014-2024. Tomando como referência o ano de 2014, as matrículas de EJA integrada à Educação Profissional (EP) tinham alcançado 2,8\% do total de matrículas de EJA. No ano de 2017, essas matrículas representavam apenas $1,5 \%$ do total, ou seja, em vez de irem em direção ao alcance da meta que era de $25 \%$, estavam retrocedendo. A variação destes dados depende da política implementada em cada dependência administrativa, todavia nenhuma delas, a continuar com o que vem sendo feito, tem condições de reverter a situação de inviabilidade desta Meta.

\section{A EJA integrada a EP e os percalços no Estado de Goiás}

Tratar a questão da integração da EJA a EP em Goiás é mais um exercício de retomada de Gramsci, pois novamente o olhar precisa ser a partir do "pessimismo da inteligência, [e do] otimismo da vontade". Digo isto porque desde a implantação do Proeja em nível nacional, o Estado de Goiás, que é o lugar de onde falo, se empenhou em participar de forma articulada nas três estratégias criadas para a implantação do Proeja: oferta de cursos, especialização para formação de professores e pesquisa para acompanhar as experiências em curso. Houve uma mobilização da Universidade Federal de Goiás, das instituições federais de formação profissional, naquele contexto Cefet/GO e Escola Agrotécnica de Goiás, desde 2006. Esta experiência se estendeu de 2006 a 2017, através de pesquisas financiadas por dois editais da Capes, um denominado Edital Proeja/Capes Setec (2006) e outro Edital do Programa Observatório da Educação (2012).

É preciso reconhecer o otimismo da vontade presente nas iniciativas desencadeadas nos espaços da educação profissional (RODRIGUES e MACHADO, 2018). Mas, essa realidade de otimismo não pode negar os grandes impasses e dificuldades que enfrentamos no Proeja desde a implantação até os dias atuais. No caso específico do Estado de Goiás, temos a seguinte quadro na matrícula de EJA integrada a EP, considerando a oferta de todas as redes de ensino. 
Quadro 3 - Matrículas de EJA na forma integrada a EP em Goiás - 2010 a 2018

\begin{tabular}{|c|c|c|c|c|c|c|c|c|}
\hline 2010 & 2011 & 2012 & 2013 & 2014 & 2015 & 2016 & 2017 & 2018 \\
\hline 899 & 979 & 1.107 & 1.528 & 1.400 & 1.320 & 1.413 & 1.637 & 1.310 \\
\hline
\end{tabular}

Fonte: Elaborada pela autora a partir do Relatório de Monitoramento do Inep (BRASIL, 2018)

Embora os dados revelem um crescimento significativo entre 2010 e 2017, diferentemente do ocorrido em nível nacional, esta matrícula do último ano representa apenas 2,1\% das matrículas totais em EJA para o Estado. Outro fator que Goiás difere da realidade dos demais estados é que essa matrícula integrada é quase exclusiva da rede federal, ou seja, do Instituto Federal de Goiás e do Instituto Federal Goiano. Pode-se dizer que neste Estado a atrofia não existe? Para responder a esta pergunta é necessário nos debruçarmos um pouco mais sobre os dados desta matrícula integrada. Para isto, optamos consultar o Censo Escolar a partir de 2014, considerando este o primeiro ano de vigência do atual PNE.

Quadro 4 - Matrículas do Curso Técnico (Ensino Médio) integrada a EJA na rede federal em Goiás, 2014 a 2018

\begin{tabular}{|c|c|c|c|c|c|c|c|c|c|c|c|c|c|c|c|c|c|}
\hline & 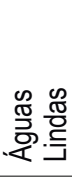 & $\begin{array}{l}\frac{00}{0} \\
\frac{0}{0} \\
\frac{0}{20}\end{array}$ & 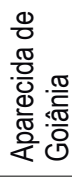 & 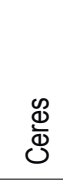 & $\begin{array}{l}\text { ர } \\
\text { O } \\
\text { E్ } \\
\text { 오 }\end{array}$ & 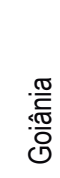 & : & 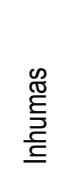 & 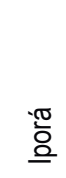 & 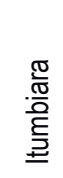 & $\frac{\text { 票 }}{\frac{\pi}{3}}$ & 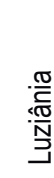 & 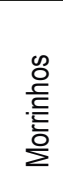 & $\begin{array}{l}\frac{0}{0} \\
\stackrel{0}{\frac{0}{2}} \\
\frac{0}{1}\end{array}$ & 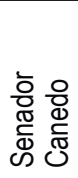 & 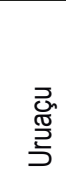 & 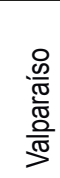 \\
\hline 2014 & 26 & 129 & 41 & 24 & 139 & 295 & 8 & 34 & 17 & 32 & 70 & 35 & 32 & 135 & - & 94 & - \\
\hline 2015 & 80 & 144 & 56 & - & 150 & 265 & 35 & 50 & 23 & 28 & 79 & 17 & 22 & - & 60 & 81 & 57 \\
\hline 2016 & 113 & 164 & 48 & - & 133 & 272 & 22 & 18 & 27 & 44 & 79 & 41 & 27 & 109 & 48 & 57 & 88 \\
\hline 2017 & 148 & 142 & 61 & - & 123 & 404 & 35 & 6 & 53 & 36 & 55 & 54 & 14 & 126 & 65 & 101 & 77 \\
\hline 2018 & - & 157 & 95 & - & 112 & 328 & 27 & - & - & 35 & 82 & 59 & 7 & 66 & 73 & 111 & 117 \\
\hline
\end{tabular}

Fonte: Censo Escolar Inep, 2014 a 2018. Elaborado pela autora.

Essas informações nos questionários do Censo Escolar no período de 2014 a 2018 sofreram algumas modificações, como por exemplo, a informação sobre os cursos integrados a EJA em 2014, 2015 e 2016 aparecia no questionário pelas categorias: EJA Ensino Fundamental Projovem Urbano e Curso Técnico(Ensino Médio) integrado a EJA, sendo que a última categoria era de cursos de Formação Inicial e Continuada (FIC), mas sem nenhuma menção a ofertas integradas a EJA. Nos anos de 2017 e 2018 são mencionadas outras categorias e a que matrículas correspondem: Curso Técnico Integrado à EJA (EJA Integrada à Educação Profissional de Nível Médio) inclui matrículas do Ensino Especial e/ou EJA; EJA Ensino Fundamental Projovem Urbano inclui matrículas do Ensino Especial e/ou EJA; Curso FIC Integrado na Modalidade EJA de Nível Fundamental inclui matrículas de Educação de Jovens e Adultos e/ou Especial; e Curso FIC Integrado na Modalidade EJA de Nível Médio inclui matrículas de Educação de Jovens e Adultos e/ou Especial. A partir desta nova denominação constam 93 matrículas da rede estadual no Município de Uruana em 2017 como Curso FIC Integrado na Modalidade EJA de Nível Fundamental e na rede federal em 2018 como Curso FIC Integrado na Modalidade EJA de Nível Médio em Iporá, que não constam dos quadros aqui apresentados.

As mudanças observadas no registro podem representar um esforço para precisar melhor a informação sobre essas duas modalidades, que vem buscando atender os sujeitos jovens e adultos de forma integrada. Isto poderá contribuir para que informações que aparecem a cada ano de forma dispersa, pontual ou em duplicidade possam ser resolvidas. Por exemplo, em 2014 as matrículas de 204 alunos, sendo 176 na rede municipal de Luziânia e 28 na rede municipal de Rio Verde aparecem lançadas como ProJovem e como EJA Profissionalizante. Localizamos matrículas de 72 alunos em Caldas Novas e 11 em Goiânia, na rede privada, que nos anos seguintes desaparecem. Em 2015 constam 174 matrículas no ProJovem Urbano no município de Luziânia também lançadas em duplicidade como EJA Profissionalizante. 
Ainda sobre os dados da rede federal, em Goiás, apresentada no Quadro 4, cabe constatar a manutenção de ofertas da EJA integrada a EP vem se mantendo, não sem dificuldades, pelo Instituto Federal de Goiás (IFG), onde se situam os Campi: Águas Lindas, Anápolis, Aparecida de Goiânia, Cidade de Goiás, Formosa, Goiânia, Inhumas, Itumbiara, Jataí, Luziânia, Senador Canedo, Uruaçu e Valparaíso. Enquanto no Instituto Federal Goiano encontram-se os Campi: Ceres, Iporá, Morrinhos e Rio Verde, sendo que destes quatro dois já não ofertam mais os cursos e em Morrinhos constam apenas 7 alunos em 2018.

Voltando a questão da atrofia, diríamos que a resistência da EJA integrada a EP para não atrofiar, na rede federal como um todo tem sido árdua. No caso do IFG, um instrumento importante que expressa a tentativa de não atrofiar, se expressa no atual PDI 2019-2023 (GOIÁS, 2019).

\begin{abstract}
Por fim, é importante salientar nossa luta para que seja mantido e fortalecido o compromisso dos Institutos Federais, com uma formação integral e integrada em seu Ensino Médio Técnico (tanto regular como na modalidade EJA), destinando a este no mínimo $50 \%$ de suas vagas; Ademais, merece destaque o seu engajamento na melhoria da qualidade da escola pública brasileira, ao destinar no mínimo $20 \%$ de suas vagas para os Cursos de Licenciatura e de formação de professoras/es. (...)

Para o período de vigência deste PDI, o Instituto Federal de Educação, Ciência e Tecnologia de Goiás tem os seguintes objetivos: 1. ministrar educação profissional técnica de nível médio na forma de cursos integrados, na proporção de, no mínimo, $50 \%$ das vagas por Câmpus, sendo prioritariamente em tempo integral, garantindo-se para a EJA a forma integrada e com oferta em todos os Câmpus; (p. 12;14)
\end{abstract}

Esse mesmo PDI informa a extinção de 7 dentre os 24 cursos de EJA integrados a EP, em seus 14 Campus, no segundo semestre de 2018. É uma preocupação esse dado, embora ele revele a movimentação dentro da própria instituição de repensar o compromisso assumido, no PDI anterior, que indicou inclusive a necessidade afirmação da modalidade fora da denominação Proeja, por isso os dados desta oferta são denominadas Técnico Integrado/EJA.

Com relação a realidade da rede estadual de Goiás, o quadro é bem mais complexo e revela com enorme pessimismo da inteligência, pois sequer foram localizados dados de matrícula de EJA integrada a EP nos níveis fundamental e médio 2014 e 2015. As matrículas na EJA integrada a EP em cursos técnicos que estão registradas encontram-se no Quadro 5, onde podem ser identificadas matrículas reduzidas e que, possivelmente, se refiram a oferta de um único curso por município.

Quadro 5 - Matrículas do Curso Técnico (Ensino Médio) integrada a EJA na rede estadual em Goiás, 2016 a 2018

\begin{tabular}{|c|c|c|c|c|c|c|c|}
\hline & $\begin{array}{l}\frac{\infty}{\overline{0}} \\
\frac{2}{0} \\
\frac{0}{2}\end{array}$ & 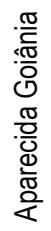 & 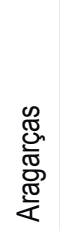 & 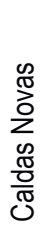 & 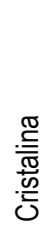 & 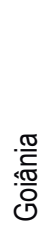 & 丞 \\
\hline 2016 & 8 & 7 & 14 & 8 & 18 & 13 & 68 \\
\hline 2017 & 6 & 4 & 13 & 7 & 14 & 7 & 51 \\
\hline 2018 & 6 & - & 12 & 7 & 16 & - & 41 \\
\hline
\end{tabular}

Fonte: Censo Escolar Inep, 2014 a 2018. Elaborado pela autora.

Neste caso podemos perceber que mais do que atrofiar, a experiência da integração entre EJA e EP no Ensino Médio não pode ser considerada existente num universo de matrícula que chegou a 44.387 alunos, conforme dados do Censo Escolar do Inep de 2018. A matrícula dos cursos identificados no quadro acima representam $0,1 \%$ dos matriculados em EJA na rede estadual de ensino. Contraditoriamente, em Goiás a atrofia da EJA não se revela apenas na não expansão da integração a EP, mas 
em sua existência "mutante", ou seja, nas diferentes estratégias utilizadas pela gestão à frente da Secretaria de Estado da Educação de Goiás, em diferentes contextos de Governo, como pode ser observado nos dois últimos exemplos. Primeiro no Quadro 6

Quadro 6 - Matrículas no Ensino Médio da EJA no Estado de Goiás, por dependência administrativa, de 2014 a 2018

\begin{tabular}{|l|r|r|r|r|r|}
\hline \multicolumn{1}{|c|}{ Dependência } & \multicolumn{1}{|c|}{2014} & \multicolumn{1}{c|}{2015} & \multicolumn{1}{c|}{2016} & 2017 & \multicolumn{1}{c|}{2018} \\
\hline Federal & 1.111 & 1.263 & 1.422 & 1.493 & 1.518 \\
\hline Estadual & 22.144 & 22.189 & 22.975 & 37.901 & 44.387 \\
\hline Municipal & 374 & 635 & 585 & 869 & 667 \\
\hline Privada & 4.061 & 2.683 & 3.263 & 4.516 & 4.163 \\
\hline Total & 27.690 & 26.770 & 28.245 & 44.779 & 50.735 \\
\hline
\end{tabular}

Fonte: Elaborado pela autora a partir dos dados do Censo do Inep, sistematizados pelo Laboratório de Dados Educacionais da UFPR.

Explicar este movimento ocorrido entre 2016 a 2018 requer de nós uma compreensão do que representa, de um momento a outro, o sistema público fecha a matrícula do primeiro ano do ensino médio noturno em todo o Estado, transferindo alunos já matriculados a modalidade EJA. Questão resultante da implantação do chamado Programa de Fortalecimento do Ensino Médio Noturno (Profen), que já foi cancelado e agora dá espaço para outra estratégia: o Programa EJA-TEC que é a experiência em polos do oferta da EJA a distância. Outra temática que precisamos aprofundar, se nos preocupamos com a forma como a educação dos trabalhadores tem sido utilizada ao longo da história para a manutenção da subalternidade. É com esta reflexão que volto a pergunta inicial deste artigo para concluir.

\section{Se ampliar é preciso, por que estão sendo atrofiados?}

A história da educação nos revela em muitos momentos que o direito a educação não se efetiva, ou se concretiza como uma oferta de acesso precário ao conhecimento e de certificação aligeirada. Para o contexto em que estamos vivendo, é possível constatar que a atrofia da experiência Proeja também pode ser entendida pelo fato deste programa, que se pretendeu constituir em política, representar uma ameaça mesmo que de forma tímida e não massiva, ao projeto de formação para a subalternidade, tão necessário ao sistema capitalista desigual e combinado.

\section{REFERÊNCIAS}

ABRAMO, Helena Wendel; BRANCO, Pedro Paulo Martoni. Retratos da Juventude Brasileira: análises de uma pesquisa nacional. São Paulo: Editora Fundação Perseu Abramo, 2005.

BRASIL. Ministério da Educação. Conselho Nacional de Educação. Câmara da Educação Básica. Parecer n. 6, de 2010. Trata das Diretrizes Operacionais para a Educação de Jovens e Adultos nos aspectos relativos à duração dos cursos e idade mínima para ingresso nos cursos de EJA; idade mínima e certificação nos exames de EJA; e Educação de Jovens e Adultos desenvolvida por meio da Educação a Distância. Brasília, DF: MEC/Inep, 2010a.

BRASIL. Ministério da Educação. Conselho Nacional de Educação. Câmara da Educação Básica. Diretrizes Curriculares Nacionais para a Educação de Jovens e Adultos. Resolução $n^{\circ}$. 3, de 15 de junho de 2010. Institui Diretrizes Operacionais para a Educação de Jovens e Adultos nos aspectos relativos à duração dos cursos e idade mínima para ingresso nos cursos de EJA; idade mínima e certificação nos exames de EJA; e Educação de Jovens e Adultos desenvolvida por meio da Educação a Distância. Brasília: MEC/Inep, $2010 \mathrm{~b}$.

BRASIL. Ministério da Educação. Instituto Nacional de Estudos e Pesquisas Educacionais Anísio Teixeira. Sinopse Estatística da Educação Básica do INEP. Brasília/DF: INEP. 2016.

BRASIL. Ministério da Educação. Conselho Nacional de Educação. Relatório do $2^{\circ}$ Ciclo de Monitoramento das Metas do Plano Nacional de Educação - 2018. Brasília/DF: INEP. 2018. 
BRASIL. Presidência da República. Lei no 13.005. Aprova o Plano Nacional de Educação PNE e dá outras providências. Disponível em http://www2.camara.leg.br/legin/fed/lei/2014/lei13005-25-junho-2014-778970-publicacaooriginal-144468-pl.html 2014.

CARDOSO, Edna Maria de Jesus. Impasses na implantação do Proeja no Ceja e no Cepss na rede estadual de ensino de Goiânia: a distância entre o dito e o instituído. 2010. 156p. Dissertação (Mestrado em Educação) - Pontifícia Universidade Católica de Goiás, Goiânia, 2010.

CARRANO, Paulo César. Educação de Jovens e Adultos e Juventude: o desafio de compreender os sentidos da presença dos jovens na escola da "segunda chance". In: REVEJ@ - Revista de Educação de Jovens e adultos, v. 1, ago. 2007, Belo Horizonte.

CURY, Carlos Roberto Jamil. Direito à Educação: direito à igualdade, direito à diferença. Cadernos de Pesquisa, n. 116, p. 245-262, jul./2002.

FÁVERO, Osmar; SPÓSITO, Marília Pontes; CARRANO, Paulo; NOVAES, Regina Reys (Orgs.). Juventude e contemporaneidade. Brasília: Unesco, MEC/Secad, ANPEd, 2007. 285 p. (Coleção Educação para Todos, v. 16). Disponível em: <http://forumeja.org.br/ colecaoparatodos>.

GOIÁS. Instituto Federal de Goiás. Plano de Desenvolvimento Institucional (PDI) 2019-2023. Goiânia-GO: 2019.

GRAMSCI, Antonio. Cadernos do cárcere. Volume 2. Edição e Tradução de Carlos Nelson Coutinho; coedição de Luiz Sérgio Henriques e Marco Aurélio Nogueira. Rio de Janeiro: Editora Civilização Brasileira. 2000.

GRAMSCI, Antonio. Cadernos do cárcere. Volume 5. Edição e Tradução de Carlos Nelson Coutinho; coedição de Luiz Sérgio Henriques e Marco Aurélio Nogueira. Rio de Janeiro: Editora Civilização Brasileira. 2002.

OLIVEIRA, Edna Castro de et al. (Organizadoras). Educação de jovens e adultos: trabalho e formação humana. São Carlos: Pedro \& João Editores, 2014.

RÊSES, Erlando da Silva et al. (organizadores). Educação de jovens e adultos trabalhadores: políticas e experiências da integração à educação profissional. Campinas: Mercado de Letras, 2017.

RODRIGUES, Maria Emília de Castro; MACHADO, Maria Margarida (organizadoras). Educação de jovens e adultos trabalhadores: produção de conhecimentos em rede. Curitiba: Appris, 2018.

SPOSITO, Marília Pontes. Jovens e Educação: novas dimensões da exclusão. Em Aberto, ano 11, n 56, out./dez. p. 43-53. Brasília: INEP. 1992.

SPOSITO, Marília Pontes. Juventude e educação: as interfaces entre a educação escolar e a educação não formal. Anais do Simpósio Internacional Juventude, Violência, Educação, Justiça. Porto Alegre: Ufrgs, 2006. 